\title{
Entrevista com Ângelo Brás Fernandes Callou
}

Por Maria Inês Gonçalves da Silva ${ }^{1}$ e Daniela de Ulysséa Leal ${ }^{2}$

Ângelo Brás Fernandes Callou é professor titular da Universidade Federal Rural de Pernambuco (UFRPE) desde 2006, universidade na qual cursou sua graduação em Engenharia de Pesca (1980). Possui título de mestrado em Extensão Rural pela Universidade Federal de Santa Maria (1986), doutorado em Ciências da Comunicação pelo Universidade Federal de São Paulo (1994) e pós-doutorado em História e Cinema, pela Universidade Nova de Lisboa (2017). Suas experiências dizem respeito a área de comunicação, agronomia e pesca, tendo atuação voltada principalmente aos temas: teoria da comunicação, história e cinema, desenvolvimento local, extensão pesqueira e extensão rural.

Sobre a sua trajetória acadêmica, como surgiu seu interesse pelo tema rural, particularmente, a comunicação rural?

Quando eu estava para me formar em Engenharia de Pesca na Universidade Federal Rural de Pernambuco (UFRPE), em 1979, desenvolvi minha monografia de conclusão de curso, cujo tema era a Extensão Pesqueira. Àquela época, eu já havia lido o livro, hoje clássico, Extensão ou Comunicação?, de Paulo Freire, e alguns trabalhos de Juan Díaz Bordenave e João Bosco Pinto. Este último, professor da Universidade Federal de Pernambuco, que havia negado sua tese de doutorado desenvolvida na América, no campo da Sociologia Rural Funcionalista Americana, para se dedicar à educação popular, numa perspectiva paulofreiriana, durante toda a sua vida. Fiz um treinamento no campo da extensão

\footnotetext{
${ }^{1}$ Bacharela em Cooperativismo Universidade Federal de Viçosa (UFV) e mestranda em Extensão Rural na UFV.

${ }^{2}$ MBA em Marketing Estratégico Universidade Federal do Tocantins) e mestranda em Extensão Rural UFV.
} 
pesqueira, promovido pela Sudepe, com o Prof. João Bosco, entre outros profissionais, ainda em 1979, estimulados que estavam, diante da Anistia Política, em promover uma Extensão na Pesca, no âmbito da comunicação horizontal.

Toda essa experiência inicial, portanto, aliada à leitura da obra de Paulo Freire, particularmente o livro Pedagogia do Oprimido, o mais importante que li até hoje na minha vida, selou, por assim dizer, o meu compromisso com esse campo de conhecimento. Isto é, a Extensão pela via da Comunicação Rural. Foi quando decidi me tornar professor universitário. E o caminho não poderia ser outro: a dedicação ao estudo, nos níveis de mestrado e doutorado.

Quando ingressei na UFRPE, como professor, em 1984, portanto, ainda muito jovem, tive o privilégio de criar o primeiro programa da disciplina Extensão Pesqueira, ainda inexistente no Brasil, numa perspectiva totalmente inovadora, na medida em que incorporava o que havia de mais atual nas discussões sobre Extensão Rural e Extensão Pesqueira, as quais combatiam a modernização do campo e da pesca artesanal, pela via da Revolução Verde e Azul, e propunham abrir canais de comunicação com esses contextos populares produtivos, considerando a participação como palavra-chave de qualquer processo de desenvolvimento da agricultura e da pesca no país. Para usar uma expressão de Paulo Freire, foi assim que construí a minha opção política no campo da Extensão Rural e Pesqueira, pela via da Comunicação Rural, à qual me dedico até hoje.

Pensando nos processos comunicacionais no meio rural e sua referência a modelos de intervenção social, é possível inferir que a comunicação, baseada no modelo difusionista, pode resultar em uma dependência do agricultor em relação ao extensionista. Por outro lado, uma comunicação mais dialógica pode promover o desenvolvimento das comunidades rurais, visto que as leva a pensar em soluções para os problemas enfrentados em suas realidades. Como você interpreta a comunicação rural atualmente? O que há de novo em relação ao tradicional debate entre difusionismo versus construtivismo? Qual das duas concepções está sendo mais empregada?

O modelo de Difusão de Inovações na Agricultura, do Prof. Everett Rogers, rendeu, na América Latina, como sabemos, uma quantidade impressionante de pesquisas 
acadêmicas, que acabaram por se tornar imprestáveis para pensar as realidades sociais, políticas e econômicas latino-americanas, particularmente do Brasil, onde foi igualmente aceito, sobretudo por aqueles pesquisadores que estudaram nas universidades de Wisconsin e Michigan. Todas as críticas, que foram sendo formuladas pelos pesquisadores pós-paulofreirianos à Difusão de Inovações, acabaram por fragilizar a sua ossatura teórica. Embora tenha havido esforços para reformulações dessa teoria, feitas pelo próprio Rogers, entre outros pesquisadores, as quais foram reunidas num importante livro dos anos 1970 - Communication and development: critical perspectives -, organizado por Rogers. Não há hoje mais espaço teórico para esse debate. Entretanto, há que se considerar que muitas dessas ideias estão, ainda, circulando por aí, como uma espécie de eco do passado, e que, muitas práticas atuais, ditas de Comunicação Rural, na verdade, são práticas difusionistas revestidas com um manto da comunicação participativa. Se lermos atentamente (faço semestralmente esse exercício com meus alunos), por exemplo, a Lei de Ater $\mathrm{N}^{\mathrm{0}}$ 12.188/2010, a despeito da importância desse instrumento legal para a Extensão Rural e Pesqueira no Brasil, ela difere, completamente, como já apontado por Francisco Caporal, da Política Nacional de Assistência Técnica e Extensão Rural (Pnater), de 2003, extinta com essa nova lei. Diferentemente da Lei de Ater, a Pnater foi construída com a participação de diversas entidades ligadas ao meio rural. Foi, sem sombra de dúvida, o documento mais avançado que se produziu no Brasil em termos de Extensão Rural e Assistência Técnica, no âmbito da Comunicação Rural.

Atualmente, considero a Comunicação Rural como uma estratégia ainda importante para que os contextos populares produtivos do meio rural e da pesca possam se desenvolver, a partir da sua própria realidade socioambiental, econômica, cultural e política, aspectos negados, historicamente, como sabemos, pelo extensionismo rural e pesqueiro tradicionais. Entretanto, é preciso salientar que, a partir dos anos 1990, no caso brasileiro, muitos vetores teóricos e experiências empíricas diversificadas passaram a ocupar o debate acadêmico e político na Comunicação Rural. Entre eles, os estudos latinoamericanos, pautados nos Estudos Culturais, desenvolvidos em Birmingham, sobre as culturas populares no capitalismo na América Latina e os processos de hibridização cultural, desenvolvidos por Néstor García Canclini; as mediações culturais nos processos de reconversão cultural nos contextos populares, propostos por Jesús Martín-Barbero; a construção da Nova Teoria da Comunicação, projeto do Prof. Ciro Marcondes Filho, na Escola de Comunicações e Artes da Universidade de São Paulo, sobre a incapacidade de 
as teorias da comunicação postas não darem mais conta dos acontecimentos comunicacionais, numa sociedade marcada pelos aparatos eletrônicos e informacionais; os processos de globalização (para usar a expressão, no plural, de Boaventura de Sousa Santos), que grassaram por aqui em ritmos diferenciados e que desaguaram nos estudos atuais sobre Desenvolvimento Local, os quais, inclusive, já incorporam as críticas de Francisco de Oliveira; além dos estudos mais recentes em Agroecologia, que vêm agrupando pesquisadores, estudantes, agricultores e agricultoras, nas reflexões, debates e experiências, ainda que haja interpretações equivocadas sobre esse campo de conhecimento. Todas essas áreas de investigação foram incorporadas, com relativa profundidade, do ponto de vista teórico e dos resultados de pesquisa empírica, à Comunicação Rural/Extensão Rural/Extensão Pesqueira. O estudante, o jovem pesquisador, que quiser hoje se adentrar no debate atual da Comunicação Rural no Brasil, deverá se debruçar sobre essa produção acadêmica para fazer suas escolhas teóricas, portanto, políticas. Todos esses estudos servem para dizer que a Comunicação Rural, à luz apenas da abordagem paulofreiriana, soa hoje como "singela", mas não se perdeu dela o que é mais essencial: o direito à palavra do outro, a diferença como reconhecimento fundamental para o desenvolvimento de um trabalho de comunicação rural, o diálogo.

\section{Como você enxerga a importância da comunicação dentro do contexto da extensão rural e extensão pesqueira? Você identifica diferentes percepções entre estes dois públicos?}

Se considerarmos a Comunicação Rural como comunicação horizontal, portanto, que vê o outro na relação dialógica, como abordado acima, os "públicos" (não aprecio muito essa expressão, pois soa para mim como extensionismo "para" e não "com” as pessoas), evidentemente, as percepções dessas populações serão diferentes. O comunicador rural/extensionista rural ou pesqueiro terá que ter conhecimento dessas diferenciações culturais. Gosto muito da compreensão cancliniana e barberiana de culturas populares (no plural), pois, na aparente similaridade cultural de cada contexto social (pescadores, agricultores familiares, camponeses, etc.), há diferentes formas de recepção nos processos de comunicação. As mediações culturais em cada contexto desses vão determinar formas de recepção e ressignificação do que vem da cultura hegemônica. Isto significa dizer que, em comunidades pesqueiras artesanais, por exemplo, ou em comunidades de agricultura familiar, ou em quaisquer contextos populares, as respostas à cultura dominante serão 
distintas, mediatizadas pelos contextos de cultura de cada território que se pretenda comunicar. Foi por esta razão que abordei as diversas tendências teóricas, como elementos fundamentais para além da Comunicação Rural pautada em Paulo Freire. Estas pesquisas no meio rural formam inauguradas, no Brasil, por Maria Salett Tauk Santos e Veneza Mayora Ronsini, nos anos 1990.

O desenvolvimento local ganha destaque em sua produção acadêmica. Como você enxerga o papel do Associativismo e do Cooperativismo neste momento em que o Brasil atravessa uma crise política que abala o regime democrático, gerando tantas perdas de direitos sociais? Associativismo e Cooperativismo podem ser vistos como elementos importantes para o desenvolvimento local?

O cooperativismo, como uma forma particular de associativismo, tem uma série de exigências legais e burocráticas, que merecem ser consideradas nas discussões com os que pretendem construir esse tipo de empresa. Mas o associativismo, em geral, deve ser visto, a meu ver, como uma forma importante de organização social e política no meio rural e pesqueiro. A própria noção de Desenvolvimento Local incorpora essa forma de organização. O fato é que, a maneira aligeirada como foram criadas as associações formais no meio rural, para as pessoas terem acesso a determinadas políticas públicas, gerou distorções consideráveis que, de certa forma, empancam o desenvolvimento dessas organizações. A participação dos associados vai diminuindo, na medida em que não veem como seu este tipo de organização. Mas há que se ficar atento para outras formas de associativismo não formal (no sentido de registro em cartório, etc.), coletivos, grupos de ajuda mútua, movimentos sociais, os mais diversos, que estão sendo construídos de maneira mais participativa e, portanto, com perspectiva de avanço social e político, tão necessário nos dias que correm.

De que forma você interpreta os impactos das novas tecnologias no âmbito do trabalho (que geralmente possuem uma referência global, em termos de concepções e orientação à padronização de práticas), no meio rural e suas relações com o desenvolvimento local?

Particularmente, aprecio a interpretação de Boaventura de Sousa Santos, como já citado, sobre os processos de globalização. Ele não concorda com essa maneira de ver os processos de globalização como homogeneizadores, padronizadores de práticas no meio 


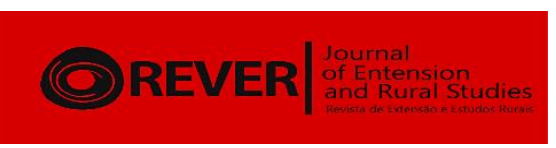

rural ou em qualquer território. A globalização, vista como um fenômeno novo, irreversível e excludente, estende seus tentáculos nos territórios de maneiras diferentes, pois não são todos os locais que interessam a ela. Embora os locais incluídos e excluídos façam parte de um mesmo processo, como se refere Tania Bacelar, a padronização, nestes termos, não se dá numa via asfaltada. Há, segundo Boaventura, locais que reafirmam sua identidade cultural nesses movimentos globalizados. A cultura é vista, portanto, como a luta contra a homogeneização. Assim, compreendo o desenvolvimento local como o lugar para pensar com os excluídos os processos de globalização para reafirmação das culturas locais (material e imaterial), como estratégia de enfrentamento do global.

Com a extinção, em 2016, do Ministério do Desenvolvimento Agrário, as suas competências passaram para a Secretaria Especial de Agricultura Familiar e do Desenvolvimento Agrário, junto à Casa Civil. Por outro lado, houve um discurso de fortalecimento da Anater. Como você enxerga os efeitos destas mudanças e seus desdobramentos para o futuro da Ater no Brasil?

Não tenho acompanhado de perto esse debate, pois tudo que vem desse atual governo é motivo, para mim, de descrença total, sobretudo quando o assunto são contextos populares desfavorecidos. Como sabemos, o Ministério do Desenvolvimento Agrário, nos últimos governos anteriores ao atual, fez, do ponto de vista da Extensão Rural, avanços nunca vistos na história do extensionismo rural brasileiro. O extinta Pnater, de 2003, foi o exemplo disso. No caso da Extensão Pesqueira, tive a oportunidade de participar de um grupo de trabalho, que redefiniu o extensionismo pesqueiro, na então Secretaria de Especial de Aquicultura de Pesca da Presidência da República (Seap/PR), à luz desse documento da Pnater.

Com o esvaziamento e a extinção de muitas das emateres estaduais, as políticas de indução do Estado para o trabalho de Extensão Rural e Pesqueira no país, por meio de editais públicos, têm se revelado como um engodo, do ponto de vista dos processos participativos, que a Lei de Ater determina. Em Pernambuco, há um esforço do Instituto Agronômico de Pernambuco (IPA) em discutir, como é o caso da Extensão Pesqueira, com as universidades, movimentos sociais e a Comissão Pastoral dos Pescadores (CPP), saídas para as dificuldades enfrentadas com o desaparecimento do Ministério da Pesca e 
Aquicultura (MPA) e dos baixos orçamentos e insuficiência de técnicos para atender às necessidades desses contextos produtivos.

Assim, se no passado nos defrontamos com o debate teórico-político no campo da Extensão Rural, hoje, penso eu que o debate deve ser mais político e para além da Extensão Rural, no enfrentamento com o atual governo e suas formas de desmantelamento das politicas sociais que, bem ou mal, contemplavam parte dos excluídos brasileiros.

Tendo em vista a estrutura agrária de nosso país, caracterizada por diversas desigualdades, principalmente no que tange à agricultura familiar e ao agronegócio exportador, como o trabalho do extensionista pode contribuir para o desenvolvimento rural e diminuição dessas desigualdades?

Acho que a luta pode e deve ser no particular, isto é, a partir das especificidades de cada contexto social excluído. Creio que os movimentos sociais vêm fazendo isto. Mas, e cada vez mais, não podemos perder de vista o poder central do Governo Temer e suas estratégias cínicas de apagar as conquistas sociais realizadas, a duras penas, nas últimas décadas.

Na sua concepção, a produção do conhecimento na área da Extensão Rural tem se tornado interesse de outras áreas de conhecimento ou ainda continua praticamente restrita a Ciências Agrárias? Como você vislumbra a saída para a fomentação deste conhecimento?

Na minha experiência na pós-graduação em Extensão Rural, ajudei a formar diferentes profissionais oriundos de campos tão diversos das Ciências Agrárias, como Direito, Psicologia, Economia, Administração, Jornalismo, Relações Públicas, Radialismo, Sociologia, Geografia, História e Fonoaudiologia, o que revela o interesse de outros profissionais no campo da Extensão Rural e Pesqueira. Sempre defendi, particularmente na Extensão Pesqueira (correndo o risco de ser criticado por colegas), que a abertura a outras áreas de conhecimento, para pensar a Extensão, alarga as possibilidades de se avançar nos aspectos teóricos da Comunicação/Extensão Rural e, sobretudo, de práticas interdisciplinares no meio rural que vão alimentar, com a participação das populações rurais, o próprio que-fazer da Extensão Rural para a renovação teórica e emancipação dos contextos sociais excluídos. 
Sobre a polissemia que você atribui à Extensão Rural, como você enxerga o papel do extensionista voltado para o futuro?

O problema com a polissemia na Extensão Rural é que muitos profissionais se arvoram a opinar, praticar e propor ações extensionistas sem um conhecimento mais aprofundado do percurso dessa disciplina em solo brasileiro. São verdadeiros absurdos que escuto por aí. Isto causa um prejuízo, não apenas no avanço das discussões mais contemporâneas da Extensão, que buscam refletir com os contextos populares o lugar do local nos processos excludentes da globalização. Na Agroecologia, por exemplo, já leio ponderações de estudiosos, alertando que nem tudo cabe nesse campo de conhecimento, além das inadequações de temas, práticas e militâncias que, apesar da sua importância, não dizem respeito diretamente à Agroecologia, pois esta possui um terreno muito particular que a define como tal. Então, acho que devemos discutir, com os nossos alunos, aquilo que Marilena Chauí propõe para sair do "eu acho que”, para "eu penso que.” Isto é, dissecar os textos de autores que já se debruçaram sobre o tema, e criticá-los, para construir "um penso que" sobre os assuntos dos nossos interesses e de nossas práticas profissionais. 